\title{
Didactic Transposition for Inferential and Analogical Thinking, Reasoning and Transfer of School Knowledge for Societal Context-of-Use
}

\author{
George N. Nditafon ${ }^{1 *}$, Emmanuel Noumi ${ }^{2}$ \\ ${ }^{1}$ Postgraduate School of Social and Educational Sciences, Faculty of Sciences of Education, University of Yaoundé I, Yaoundé, \\ Cameroon \\ ${ }^{2}$ Laboratory of Plant Biology: Higher Teachers' Training College, University of Yaoundé I, Yaoundé, Cameroon \\ Email: *nditafong@yahoo.com
}

How to cite this paper: Nditafon, G.N. and Noumi, E. (2018) Didactic Transposition for Inferential and Analogical Thinking, Reasoning and Transfer of School Knowledge for Societal Context-of-Use. Open Access Library Journal, 5: e4785.

https://doi.org/10.4236/oalib.1104785

Received: July 16, 2018

Accepted: August 11, 2018

Published: August 14, 2018

Copyright $\odot 2018$ by authors and Open Access Library Inc.

This work is licensed under the Creative Commons Attribution International License (CC BY 4.0).

http://creativecommons.org/licenses/by/4.0/

\begin{abstract}
This study demonstrates the effectiveness of Klopfer's taxonomy and a candidate hypothetico-deductive thinking and reasoning theory of didactic transposition, in teaching critical thinking skills, analogies and transferability of knowledge for problem-solving now and for the future in the experimental sciences. It was conducted in four socio-cultural zones of Cameroon involving 307 high school students (166 English-speaking and 141 French-speaking). Four lessons on the human skeleton were used. A researcher-made Likert questionnaire to investigate the level of appropriation of the tool was administered in the pre- and post-intervention treatments. Data was analysed in SPSS v.20.0 and pair-wise t-test analysis revealed a significant difference in mean scores between pre- and post-interventions with a moderate effect size. A two-way factorial ANOVA to determine the main and combined interaction effects of distal variables, further confirmed the results. Within limits, the results led to the conclusion that Klopfer's taxonomy and the candidate theory enhanced the development of critical thinking skills, analogical reasoning for transferability and problem-solving in novel contexts among high school students. From the results, we recommended the adoption of the candidate theory as framework guide for classroom practice in teaching the experimental sciences.
\end{abstract}

\section{Subject Areas}

Education

\section{Keywords}

Didactics, Hypothetico-Deductive Thinking, Critical Thinking, Reasoning, 


\section{Introduction}

\subsection{Background}

Science and technology play a fundamental role in the development of any country. On-going science and technology curriculum reforms in Cameroon secondary education prescribes a complete paradigm-shift from a purely knowledge-based to the knowledge-utilization approach commonly referred to as the competency-based approach to teaching and learning [1]. Among the competencies prescribed in this new dispensation for lifelong learning of the experimental sciences are critical thinking skills, namely the development in students of:

1) inferential thinking and creative skills;

2) the spirit of initiative and enterprise;

3) the taking of informed decisions, acting on them and tackling life problems in different contexts; and

4) self-assertion, autonomy, social and civic responsibility skills.

All of these critical thinking skills are necessary for the citizens of the rapidly changing $21^{\text {st }}$ century and beyond [2] [3] [4] [5].

The new classroom practice mandates all teachers in secondary education to introduce their lessons using real life contextual problem situations. By prescribing this, the reform in other words is calling on teachers to adopt a problem-based learning (PBL) approach to teaching. This means that scientific knowledge should be acquired for problem-solving and not for its own sake. Contextualizing brings learners face-to-face with their own local realities that favour the establishment of a concrete link between school knowledge and its utility in society [6]. In addition, a major profile of the learner in this reform is the insistence on their ability to use critical thinking skills (comparison, inferences, analogies and transfer of knowledge from one context of use to another), reasoning and the scientific approach to seek solutions to daily problems. Changing classroom practice therefore calls for re-planning lessons to include the integration of real world contextual life problem-solving skills [2]. Although there are these policy level commitments, practical implementation remains problematic requiring teacher re-training alongside reforming initial teacher training programs.

\subsection{Problem}

In Cameroon schools today, the sciences are taught as packages of disjointed and isolated facts as if there were no relationship between them and other disciplines, and between them and other aspects of life [1]. Teaching is in the most part abstract and not related to contextual life situations and therefore devoid of rele- 
vance to the learner [2] [7] [8]. There is the absence of an appropriate framework for didactic transposition and teaching to enable learners learn how to think critically, reason, construct and transfer their knowledge to seek solutions to life challenges [2] [3] [4] [7] [8]. Marin and Halpern [4] assert that in the USA there is little empirical evidence to help educators decide how to teach in ways that enhance critical thinking, despite recognition that the development and transfer of critical thinking skills are primary goals for education. Fisher [9] argues that although many teachers claim to teach their students indirectly how to think, educators doubt the effectiveness of such teaching because "most students simply do not pick up the thinking skills in question". Paul, Linda, and Ted [10] reported that of $89 \%$ of the teachers in their sample who claimed critical thinking to be a primary objective of their teaching; only $9 \%$ were clearly teaching with a focus on critical thinking meaning that most teachers have only a vague understanding of the concept. Stapleton [11], Thurman [12], and Bataineh and Alazzi [13], have variously reported the lack of knowledge or understanding of critical thinking and how it should be taught and practiced among school teachers. All of these mean that the effective teaching of good thinking is rare, and hence, there is a need for continuing systematic teaching of how to think and reason to students. Although the usefulness of various critical thinking interventions and programs has been demonstrated and reported, shortcomings, "gaps and even apparent contradictions" [14] of some of them do exist. Hatcher [15] is convinced that numerous important questions need to be examined if the goal of teaching critical thinking is to be met. Most thinking programs draw heavily on Bloom's taxonomy (though with some modifications). This prompted these researchers to lead with a critical analysis of Bloom's classification and to offer alternative, though related, approach informed by Klopfer's [16] taxonomy and the nature-semiotic thinking process called the hypothetico-deductive thinking and reasoning framework. More specifically, the program is a framework for infusing critical thinking, reasoning and transferability skills into lesson contents using the technique of identification of analogies. This alternative thinking program facilitates the linking of concepts to situations-of-use and therefore the bridging and transfer of knowledge that can lead to the expansion of the student's realm of thinking, reasoning, and problem-solving [2] [3] [4] [7] [8] [17]. Klopfer's taxonomy which has an inbuilt bridging characteristic suitable for didactic transposition and learner-centred teaching is better adapted to the teaching of the experimental sciences though it is not widely known and used in organising teaching and learning in schools.

This led to the formulation of the following research question:

Can cognitive remediation informed by Klopfer's taxonomy and the hypothetico-deductive thinking and reasoning candidate theory for didactic transposition, teaching and learning of the experimental sciences influence high school student's ability to learn how to think critically, reason, and transfer their knowledge to seek solutions to real life societal problems now and for the unknown 
future?

From this question, the following null research hypothesis was formulated to guide the investigation:

Ho: There is no significant difference in variances between summated mean scores of respondents on both the predictor and outcome dependent variables before and after intervention when selected categories of Klopfer's taxonomy and the nature-semiotic hypothetico-deductive thinking and reasoning program inform didactic transposition and teaching in the experimental sciences.

\section{Methodology}

The study employed a cocktail of diagnostic Likert scale questionnaire response type items with proposals of different levels of responses to respondents to evaluate and therefore demonstrate the effectiveness of the nature-semiotic hypothetico-deductive thinking and reasoning candidate theory [2] in developing critical thinking, reasoning and transferability skills in high school students. Items on the constructs were formulated into questions with options provided to respondents to strongly agree, agree, neutral, disagree and strongly disagree to determine their different levels of judgment and therefore appropriation of the concept. The study was a quasi-experimental design and used a within-subject analysis complemented by a two-way factorial ANOVA. The quasi-experimental model was adopted because there are already existing class structures in the educational system in which schools are constrained to cover syllabuses within a limited and inelastic pedagogic time. Also, schools and parents would oppose any attempt to experiment with their children if a strictly experimental design were to be adopted, since this would require restructuring the existing class setting and introducing new subject matter content. Contextual problem-solving now and in the future (unknown) constituted the dependent variable. In order to measure this variable it was operationalised by defining indicators (independent variables) in Klopfer's taxonomy and the hypothetico-deductive thinking and reasoning program. The 307 high school students, who took part in the study, were distributed according to four socio-cultural zones of Cameroon as follows: 82 (North West and West Regions), 62 (South West and Littoral Regions), 94 (Centre, South and East Regions) and 69 (Adamaoua, North and Extreme North Regions). In all, four bilingual high schools (2 Public, 1 Lay Private and 1 Denominational) were involved. The bilingual character of the schools offered the opportunity to sample both English- and French-speaking students on the same campus without having to shuffle between many schools. Working in these four socio-cultural zones was a precautionary measure to ensure representativeness and the possibilities of generalisability of results.

\subsection{Sampling}

Sampling was by the De Landsheere [18] method involving a simple random sampling technique. The already existing school structure was used and the 
study proceeded by randomly assigning codes to them. This was followed by a simple balloting to designate the target, sampled and sample populations. The sampling was done in two stages involving the different school clusters. The cluster codes were written on pieces of paper, folded firmly and shuffled. A six year old child was asked to draw one of the folded pieces of paper after which the rest was reshuffled and a second and third draws were done to select the public, denominational and lay private schools in each case in the school cluster category. The process was repeated to select the class for the study.

\subsection{Lessons}

The study was conducted with four (4) lessons of 60 minutes duration each on the human skeleton. These were: 1) bone structure and function; 2) skull or cranium; 3) vertebral column, ribcage and lumbar vertebrae; and 4) appendicular skeleton. The preparation and teaching of each of these lessons was guided by Klopfer's taxonomy and the hypothetico-deductive thinking and reasoning model.

\subsection{Questionnaire}

The questionnaire was designed to obtain data on respondent's ability to appropriate the hypothetico-deductive thinking tool in problem-solving as well as personal data on their demographic, educational and socio-economic backgrounds which constituted the distal variables. Though the distal variables are not the principal variables under investigation, they are nevertheless important because they could have possible influence on the learner's ability to appropriate the thinking and reasoning process. The first step in the development of the questionnaire was to generate an initial pool of ideas around the target constructs under investigation by jotting down as many potential test items, ideas and statements as possible that spontaneously came to mind. This strategy served as a precaution to avoid missing out on some important aspects of the constructs. Nevo [19] holds that this approach maximises the face validity of the measurement scale. The second step involved organising the ideas jotted into researcher-made Likert scale type questionnaire. The initial questionnaire consisted of 117 items distributed into 12 on distal factors (school, gender, age, educational subsystem, region of origin, sponsor, educational level of sponsor, and their marital status); 89 on Klopfer's taxonomy and the hypothetico-deductive thinking and reasoning framework); and 16 on life skills and competences for problem-solving.

Of the 89 items on Klopfer's taxonomy and the hypothetico-deductive thinking and reasoning framework:

1) 19 were on the identification of problem-solving characteristics and properties of the human skeleton (CS);

2) 18 on deciphering and stating the problem necessitating the possession of the characteristics and properties identified (DSP); 
3) 18 on considering the characteristics of the skeleton as its know-how in solving problems (SKH);

4) 18 on application of the skeleton's know-how in other areas of the same discipline and in other disciplines (ASKHOASDD); and

5) 16 on application of the skeleton's know-how in technology including society (ASKHT).

The items were developed in English and translated into French. Two alternative methods were used. Two parallel independent translations into French from the original English were done and then compared to a third equally independent translation by a third person. Back-translation into English of the French version was done by a fourth person to verify whether the translation was a faithful replica of the original English version. At the end there were two questionnaire of reference in English and in French.

The completed questionnaire was piloted to readjust the structure, content, length and to improve coherence and understanding. A two-plan (qualitative and quantitative statistical analysis) approach to piloting was adopted to test the feasibility of the questionnaire. Piloting was conducted on 50 high school students of Government Bilingual High School Etoug-Ebe in Yaoundé, split into 30 Upper Sixth students of the English-speaking subsystem and 20 Terminale D students of the French-speaking subsystem. This was done during the period ranging from the last week of September to the first week of December, 2015. On the statistical plan the differential item functioning (DIF) was assessed to ascertain whether the questionnaire is invariant with respect to gender or cultural background of the respondents and to establish the reliability and validity of measurements, as well as gain professional advice on the research questions and hypotheses [20]. The complete piloted data were verified using SPSS v.20.0 for their suitability for use in parametric and regression analyses.

\subsection{Data Collection and Treatment}

\subsubsection{Data Collection}

It was not easy to obtain approval from both the school administration and parents to conduct the experiment. Assurance had to be given to the school administration that existing class structures will not be offset and there was no additional pressure on the school timetable for a new slot to conduct the experiment. On the part of the parents, assurances that the experiment was not going to interfere with the regular content of the curriculum, but rather that it was going to improve on their children's ability to thinking critically and make school knowledge relevant by placing it within its context-of-use they readily adhered. After obtaining the approval from these major stakeholders in the education of the child, the teachers who willingly accepted to participate in the research were trained in the methodology and the questionnaire was first administered as a pre-test. After pre-testing the lessons were taught by the class teachers followed by a post-test assessment consisting of the same questionnaire as in the pre-test. 
To minimise the effect of familiarity due to pre-exposure, the items of the questionnaire were shuffled and the stem slightly altered ensuring that the meaning of each item remained the same. The purpose of the experimentation was not disclosed to the students to minimise the Hawthorne as well as the Henry effects, [18]. Students were however informed that a particularly novel didactic approach which seeks to help them learn how to think, how to reason in a structured way and transfer their constructed knowledge to seek solutions to real life contextual problems will be used.

\subsubsection{Data Treatment and Analyses}

Data treatment consisted of careful coding and scoring of the pre- and post-intervention questionnaire by the researcher to eliminate possible discrepancies in judgments if the different class teachers were allowed to code and score them. The coded data were keyed in and sorted to identify and correct data entry errors, identify and manage outliers and missing values, verify assumptions for statistical analysis and transform the data for subsequent parametric analyses. The identification of outliers was necessary to minimise the possibilities of both Type I ("falsepositive") and type II ("falsenegative") errors [21] [22] [23]. A dimension reduction with Principal Component Analysis (PCA) as method of extraction and Verimax rotation with Kaiser Normalisation was conducted to reduce the number of items on the scale. In this analysis the interest was on the anti-image correlation matrix which provided Measures of Sampling Adequacy (MSA) values for each item on the scale. This statistic was used to decide which item to retain on the scale with items having a MSA values $<0.5$ removed while those with MSA values $\geq 0.5$ were retained.

Content validity was assured by preparing and submitting to experts (course teachers) for appreciation and approval of the researcher-made questionnaire. Criterion validity was assured by developing questions that required inductive and deductive reasoning as criteria for problem solving in different contexts requiring the mobilisation of knowledge and other resources from the hypothetico-deductuve thinking and reasoning framework process. Construct validity was assured through a trial test run administered to 50 randomly selected students of the study sample. An internal consistency plan to check reliability was adopted. In the first stage a PCA test run was realised to verify whether items for each type of construct "hung together". In the second stage, Cronbach's alpha coefficient for each item, subscale and total scale were computed. This was to ensure that whether individually or combined, the scale was actually measuring what it was intended to measure. Since this study involved working with students in a class, the effect of peer influence on one another was mitigated by setting a more stringent alpha level of $\rho<0.01$ [22]. The cleaned data were transformed into a continuous scale by summating the item scores to give an overall score for each construct investigated. Summation as a way of treating Likert scale data was justified by the Central Limit Theorem which includes ANOVA, t-test and regression procedures [21] [22] [23]. Information on the 
new variable names was carefully recorded in the codebook to guide subsequent analyses and manipulation. This was followed by a further verification of errors if any in the newly created variable and the running of a descriptive statistics to identify patterns, trends and errors and above all to verify the assumptions for regression analyses. Verification for linearity, normality, collinearity, multicollinearity, autocorrelation and homoscedasticity were conducted using various SPSS programs.

Statistical data analyses were both descriptive and inferential. Descriptive statistics was by the generation of univariate statistics of frequency distribution tables, and combined histograms and lined graphs for the individual and summated variables to explore the structure of the data. Inferential statistics consisted of exploring differences between interventions using paired samples t-test, and two-way factorial ANOVA. The calculated $t$-values from the $\mathrm{t}$-test technique were used to determine the probability ( $\rho$-values) within the lower and upper bound limits of a confidence interval (CI) of $99 \%$. With a degree of significance below the $\mathrm{CI}$, the null hypothesis stated in the problem section above was rejected and vice versa. The factorial ANOVA technique was employed to assess the influence of two or more independent variables on a dependent variable within the same analysis. This plan enabled the investigation of the main as well as the combined or interaction effect of certain independent distal variables on the dependent or outcome variable. For the independent variables with multiple levels a post-hoc multiple comparisons was further realised to locate the exact level contributing the most or least effect. Cohen's effect size was estimated alongside the $\mathrm{t}$-test to establish the magnitude of the difference between the two samples at pre- and post-intervention and to minimize the shortcomings of the $\rho$-value estimation [24] [25] [26] [27] [28]. Combining information about effect size with the $\rho$-value for significance tests led to a better appreciation of the difference between groups. Eta squared $\left(\eta^{2}\right)$ which gives an estimate of the magnitude of the difference between groups as a more robust statistic for rejecting or upholding the null hypothesis in analysis of variance, was also computed and interpreted.

\section{Results and Interpretation}

\subsection{Quality Control and Quality Assurance}

After the piloting process questionnaire items were readjusted and reorganised around each construct, with redundant items removed to cover the following themes of the theoretical postulate:

1) identifying and describing the problem-solving characteristics of the skeleton-Klopfer's taxonomy (reduced from 19 to 14 items);

2) deciphering the problem solved by the possession of the identified characteristics-hypothetico-deductive thinking and reasoning model (reduced from 18 to 16 items);

3) considering the identified characteristic as the skeleton's know-how in 
problem-solving (from 18 to 13 items);

4) application of know-how in other areas of the same discipline and other disciplines (interpolation)_Klopfer's taxonomy (reduced from 16 to 14 items);

5) application of know-how in technology including society (extrapolation)-reduced from 16 to 11 items; and

6) acquisition of life skills and competences for problem-solving (reduced from 16 to 11 items).

Prior to descriptive and inferential analyses, 8 missing values all representing less than $5 \%$ of the total data set with no regular pattern of distribution in their occurrence were identified and corrected. In the correction of data entry errors, no variable was tested for possibility of a systematic relationship between missingness because there was no case with up to $5 \%$ missing values. In a normality test, the mean and 5\% trimmed mean values were not very far apart indicating that the presence if any of outliers in the data set may not significantly affect the results of the analysis. The Kolmogorov-Smirnov $\rho$-value of 0.001 for some variables under investigation led to the rejection of the null hypothesis of normality in the data set in favour of non-normality. Hence generally, the entire data set was found to consist of a mix of normal and non-normal distribution. The non-normally distributed variables violated the assumptions for t-test and regression analysis which was further confirmed by the shapes of the normal Q-Q plots, detrended Q-Q plots and boxplots for each variable. For this data to fit $\mathrm{t}$-test and regression analyses, it was transformed using the summation function of SPSS v.20.0. This yielded the following new variables:

1) Total Characteristics of the human Skeleton (TCS);

2) Total Deciphering and Stating the Problem necessitating the possession of the characteristics and properties identified (TDSP);

3) Total Skeleton's Know-how in solving problems (TSKH);

4) Total Application of the Skeleton's Know-How in Other Areas of the Same Discipline and in other Disciplines (TASKHOASDD);

5) Total Application of the Skeleton's Know-How in Technology including society (TASKHT); and

6) Total Acquisition and transfer of Problem-Solving Skills and Competences (TAPSSC).

Verification of the assumptions for parametric analyses on the summated data yielded a Durbin-Watson (DW) statistic of 2.251 and an ANOVA test of global significance of 0.926 respectively indicating that the regression null hypothesis of "coefficients of all independent variables equal zero" is rejected in favour of the alternative hypothesis. Based on this therefore, the data was found fit for regression analysis. Conversely, examination of the correlation matrix generated alongside the Durbin-Watson statistic revealed high correlations between some of the independent variables that predicted the dependent variables. This is an indication of possible multicollinearity and therefore an impending problem with the determination of the degree of the effect of each predictor variable on the dependent variable. The tolerance value for the independent variables ranged 
from 0.294 to 0.459 further suggesting possibility of multicolinearity. To resolve this problem, items on the summated scale with similar correlation coefficients equal to or close to unity were combined into one or one of them simply removed. After this, the Variance Inflation Factor (VIF) values which were all below 10 with a conditional index $<30$ for all the independent variables suggested that the assumption of the absence of multicollinearity in the data set is respected. On the overall, the results revealed that the distribution of the summated data set reasonably respected the conditions for regression analysis more so than the non-summated data as seen in Table 1 and Table 2.

In a linearity and homoscedasticity test, the histogram showed a normal distribution with a mesokurtic aspect; the P-P Plot displayed a roughly cigar-shaped distribution; and the scatter plot did not display patterns around the predicted values represented by the horizontal straight line. All of these pointed to the fact that the dependent variable's variability is equal across all values of the independent variable in the data set. This confirmed that the summated data set is homoscedastic. These results are visualised in Figure 1 and Figure 2.

\subsection{Reliability Check}

A test of Cronbach's alpha yielded a value based on standardised items of 0.901 . The item total statistics also yielded values ranging from 0.894 to 0.898 for all the initial variables in the study. These results confirm a very high internal consistency of the measurement scale and therefore a good reliability according to [29]. Hence, collectively and individually all the items had very high Cronbach's alpha values confirming the fitness of the data for regression analysis.

\subsection{Descriptive Results of the Hypothetico-Deductive Thinking and Reasoning Constructs}

Paired samples descriptive statistics of the pre- and post-intervention data of the summated scales (TCS 1 and 2, TDSP 1 and 2, TSKH 1 and 2, TASKHOASDD 1 and 2, TSKHT 1 and 2 and TAPSSC 1 and 2) yielded results visualised in histograms and line graphs in Figures 3-5.

Table 1. Coefficients ${ }^{\mathrm{a}}$ of independent variables with collinearity statistic.

\begin{tabular}{|c|c|c|c|c|c|c|c|c|c|c|}
\hline \multirow{2}{*}{ Model } & \multicolumn{2}{|c|}{$\begin{array}{l}\text { Unstandardized } \\
\text { Coefficients }\end{array}$} & \multirow{2}{*}{$\begin{array}{c}\text { Standardized } \\
\text { Coefficients } \\
\text { Beta }\end{array}$} & \multirow{2}{*}{$\mathrm{T}$} & \multirow{2}{*}{ Sig. } & \multicolumn{3}{|c|}{ Correlations } & \multicolumn{2}{|c|}{ Collinearity Statistics } \\
\hline & B & Std. Error & & & & Zero-order & Partial & Part & Tolerance & VIF \\
\hline (Constant) & 28.592 & 3.307 & & 8.646 & 0.000 & & & & & \\
\hline TASKHT & -0.014 & 0.105 & -0.012 & -0.135 & 0.893 & 0.025 & -0.008 & -0.008 & 0.459 & 2.177 \\
\hline TSKH & 0.012 & 0.140 & 0.008 & 0.083 & 0.934 & 0.042 & 0.005 & 0.005 & 0.332 & 3.013 \\
\hline TDSP & 0.021 & 0.113 & 0.020 & 0.183 & 0.855 & 0.046 & 0.011 & 0.011 & 0.294 & 3.401 \\
\hline $\mathrm{TCS}$ & -0.043 & 0.099 & -0.039 & -0.434 & 0.665 & 0.019 & -0.025 & -0.025 & 0.423 & 2.362 \\
\hline
\end{tabular}

a. Dependent Variable: Total acquisition of problem-solving skills and competence. Source: Data collected and analysed by Nditafon (2016). 
Table 2. Collinearity diagnostics ${ }^{\mathrm{a}}$ with condition index.

\begin{tabular}{ccccccccccc}
\hline \multirow{2}{*}{ Model } & \multirow{2}{*}{ Dimension } & Eigenvalue & Condition & \multicolumn{5}{c}{ Variance Proportions } \\
\cline { 7 - 10 } & & Index & (Constant) & TASKHT & TASKHOASDD & TSKH & TDSP & TCS \\
\hline $\mathbf{1}$ & 5.938 & 1.000 & 0.00 & 0.00 & 0.00 & 0.00 & 0.00 & 0.00 \\
$\mathbf{2}$ & 0.021 & 16.842 & 0.74 & 0.01 & 0.06 & 0.00 & 0.06 & 0.04 \\
$\mathbf{3}$ & 0.014 & 20.501 & 0.03 & 0.17 & 0.14 & 0.04 & 0.07 & 0.50 \\
$\mathbf{4}$ & 0.011 & 23.657 & 0.18 & 0.68 & 0.00 & 0.03 & 0.04 & 0.38 \\
$\mathbf{5}$ & 0.010 & 24.309 & 0.01 & 0.00 & 0.78 & 0.18 & 0.20 & 0.00 \\
$\mathbf{6}$ & 0.006 & 28.592 & 0.04 & 0.15 & 0.01 & 0.74 & 0.63 & 0.08 \\
\hline
\end{tabular}

Source: Data collected and analysed by Nditafon (2016).
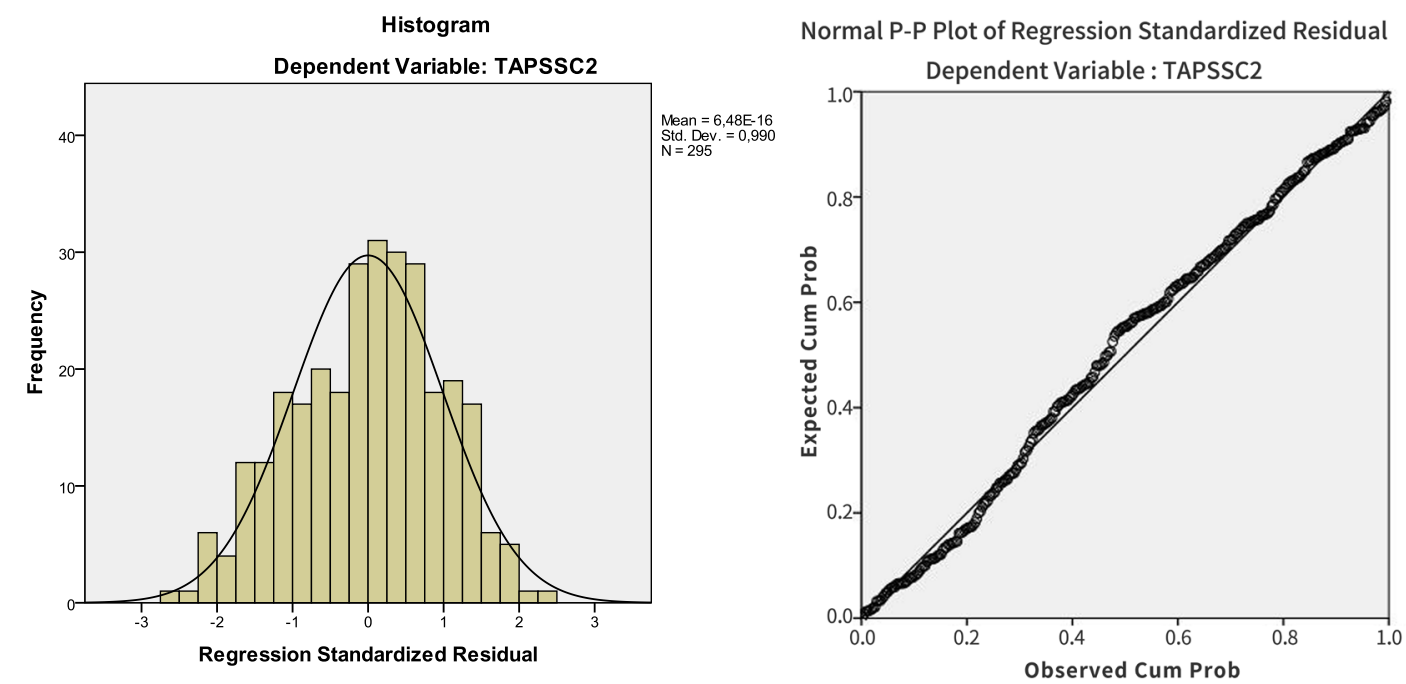

Figure 1. Left: Histogram of the distribution of points in the outcome variable-Appropriation of problem-solving skills and Right: Normal P-P Plot of the same data. Source: Data collected and analysed by Nditafon (2016).

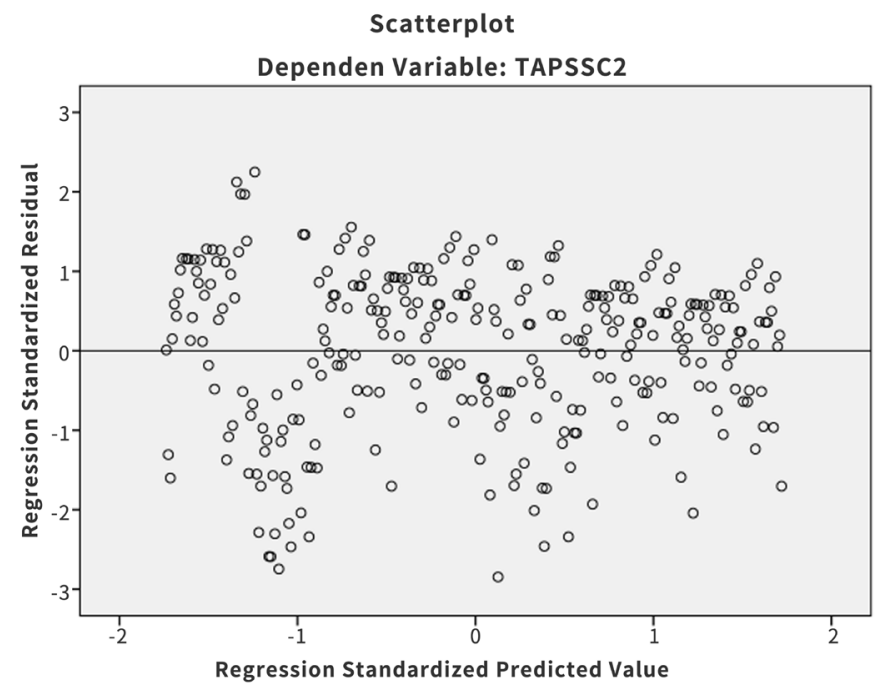

Figure 2. Scatterplot for the outcome dependent variable. Source: Data collected and analysed by Nditafon, 2016. 

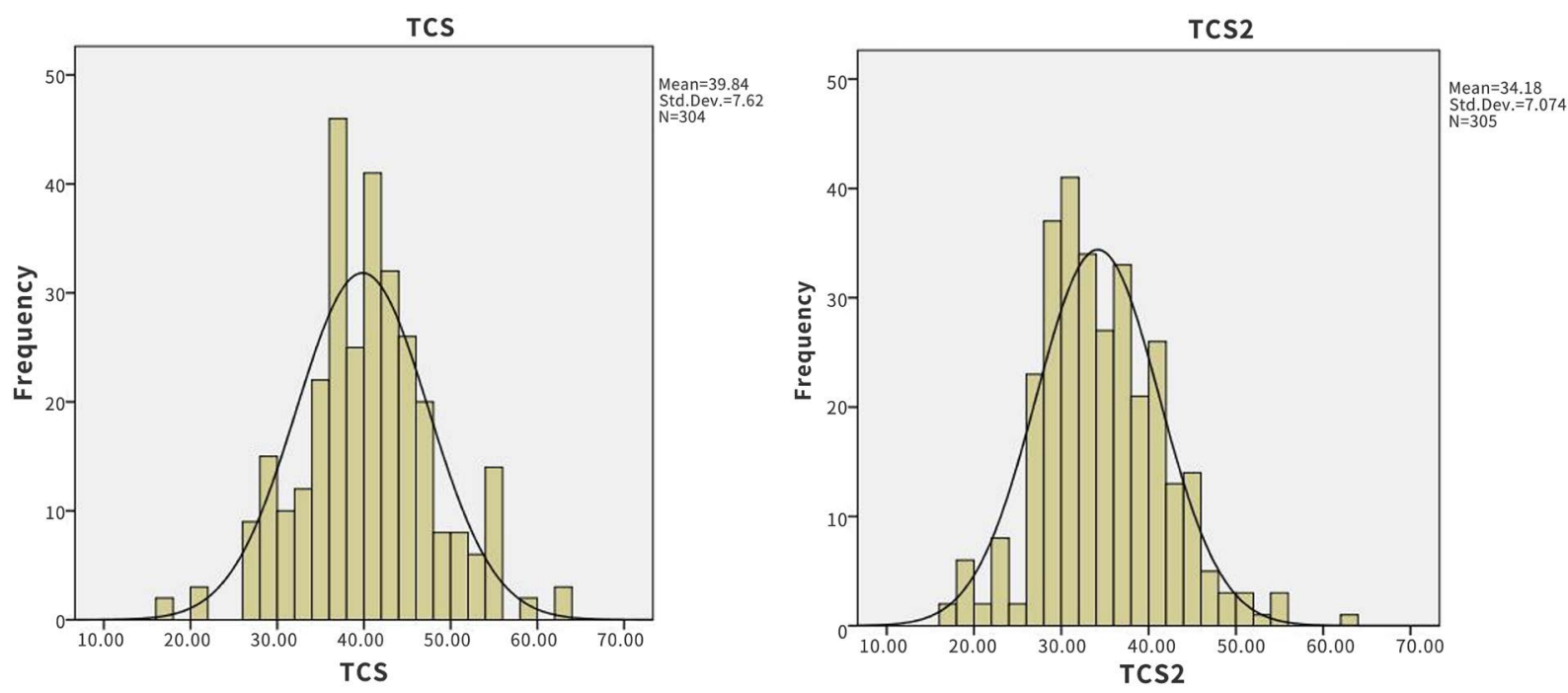

Figure 3. Distribution of scores in summated scale TCS Vs TCS-Identification of problem-solving characteristic Source: Data collected and analysed by Nditafon (2016).
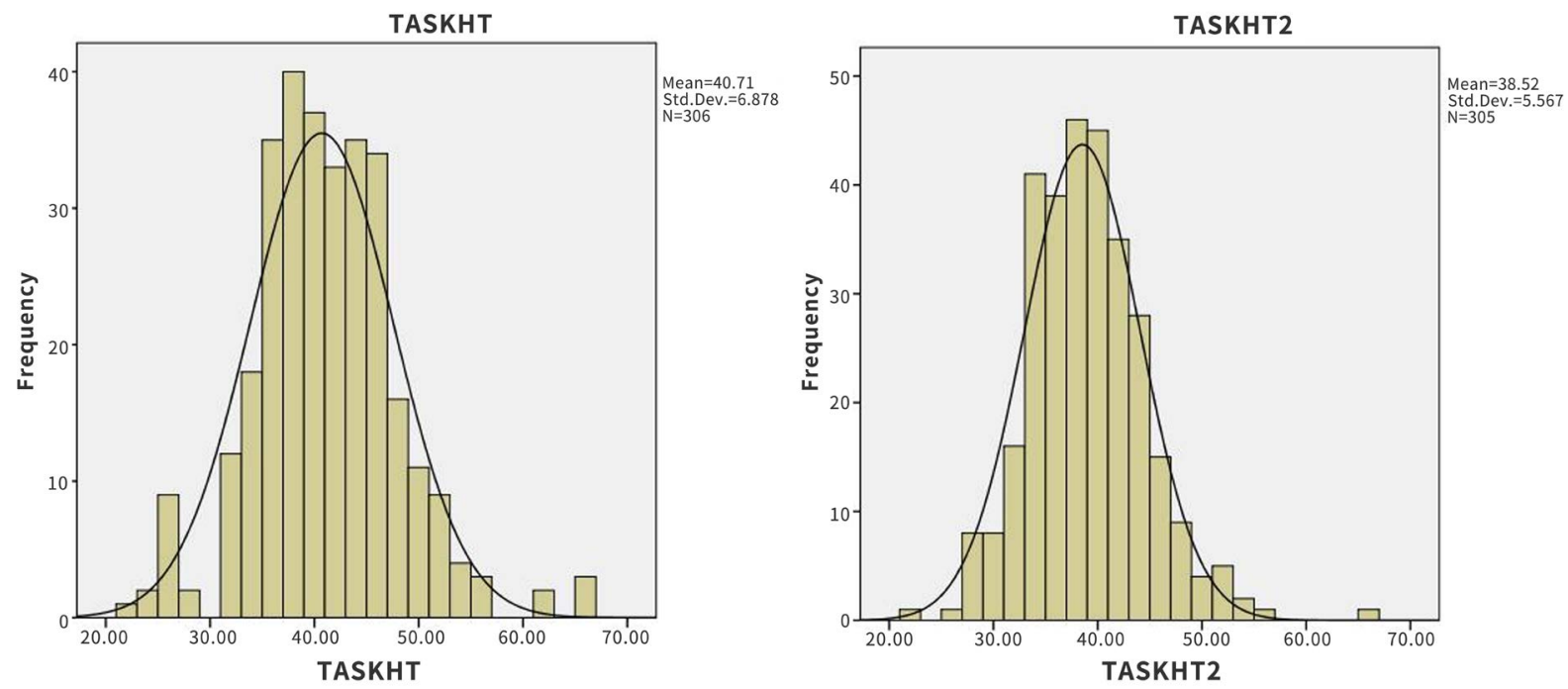

Figure 4. Distribution of scores in the summated scales TASKHOASDD Vs TASKHOASDD 2 (Interpolation of skeleton's know-how) and TASKHT Vs TASKHT 2 (Extrapolation of skeleton's know-how) Source: Data collected and analysed by Nditafon (2016).

In all the constructs investigated, all pre-intervention data sets displayed an approximately mesokurtic aspect. Differences were seen in the post-intervention data as follows:

1) In identification of problem-solving characteristics, post-intervention data also showed an approximately mesokurtic aspect, suggesting that the identification of adaptive characteristics of organisms, objects and phenomena is not much of a problem to learners since this constitutes part of the regular curriculum in Cameroon schools at this level;

2) For deciphering and stating the problem-solved by the identified characteristics, post-intervention data were more platykurtic suggesting that the use of the 

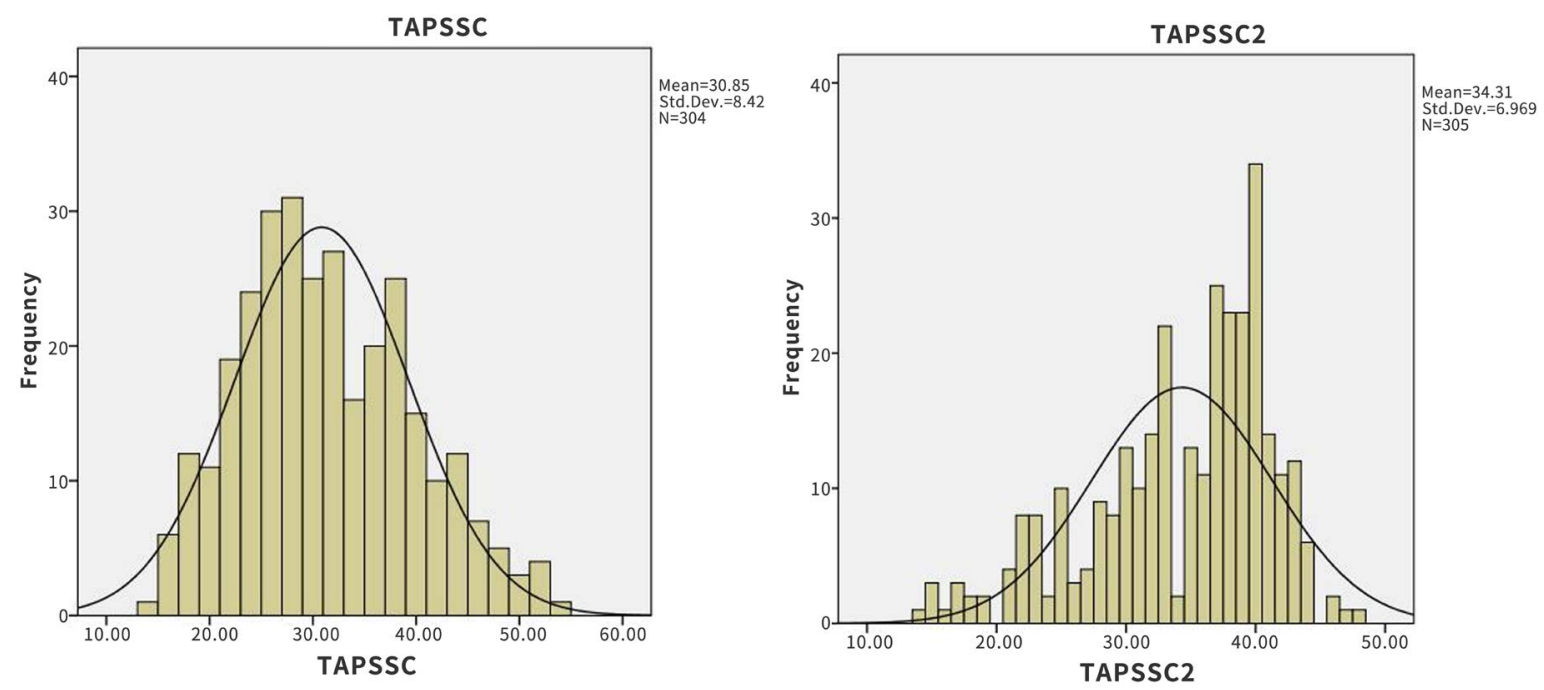

Figure 5. Distributionof scores in the summated scales TAPSSC Vs TAPSSC 2. Appropriation of Life skills. Source: Data collected and analysed by Nditafon (2016).

model resulted in gains in reasoning ability of students;

3) With respect to identification of the skeleton's know-how, post-intervention scores were more leptokurtic meaning that a greater number of respondents conglomerated towards the centre of the distribution;

4) Concerning the interpolation and extrapolation of skeleton's know-how to other areas of the same discipline, other disciplines, and technology including society, post-intervention scores were all leptokurtic in aspect.

5) In the appropriation of life skills category, a rather interesting distribution was observed. Post-intervention distribution was more platykurtic. This suggested that even though there is a difference between pre- and post-interventions, in real life situations, behaviours are determined by a combination of factors interacting together rather than by a single factor acting alone.

\subsection{Hypothesis Testing}

Inferential statistics was conducted to verify the level of significance of the research hypothesis stated earlier in the problem section of this report.

From the descriptive results presented above, it can easily be assumed that the changes observed are significant. Descriptive statistics in itself is not sufficient to enable the taking of such a decision. As a result, a within group pair-wise t-test analysis yielded the following results presented in Table 3 and Table 4.

From these results it was observed that while performance of respondents on the TCS and TSKH constructs showed a moderately significant positive correlation between pre- and post-interventions treatments, $(\mathrm{r}=0.36, \rho<0.001$ and $\mathrm{r}=$ $0.30, \rho<0.001$ respectively) according to Cohen [30], those for the constructs TDSP, TASKHOASDD, TASKHT and TAPSSC all displayed a high significant positive correlations between pre- and post-intervention treatments with correlation coefficients of $(\mathrm{r}=0.40, \rho<0.001),(\mathrm{r}=0.43, \rho<0.001),(\mathrm{r}=0.47, \rho<$ $0.001),(\mathrm{r}=0.45, \rho<0.001)$, respectively. These results imply that those who 
Table 3. Paired samples correlation for pre- and post-interventions.

\begin{tabular}{ccccc}
\hline & Constructs & N & Correlation & Sig. \\
\hline Pair 1 & TCS and TCS 2 & 303 & 0.356 & 0.000 \\
Pair 2 & TDSP and TDSP 2 & 306 & 0.399 & 0.000 \\
Pair 3 & TSKH and TSKH 2 & 304 & 0.302 & 0.000 \\
Pair 4 & TASKHOASDD and TASKHOASDD 2 & 307 & 0.433 & 0.000 \\
Pair 5 & TASKHT and TASKHT 2 & 305 & 0.469 & 0.000 \\
Pair 6 & TAPSSC and TAPSSC 2 & 302 & 0.447 & 0.000 \\
\hline
\end{tabular}

Source: Data collected and analysed by Nditafon (2016).

Table 4. Paired samples t-test for pre- and post-interventions.

\begin{tabular}{|c|c|c|c|c|c|c|c|c|c|}
\hline & & \multicolumn{5}{|c|}{ Paired Differences } & \multirow{3}{*}{$t$} & \multirow{3}{*}{$\mathrm{df}$} & \multirow{3}{*}{$\begin{array}{c}\text { Sig. } \\
\text { (2-tailed) }\end{array}$} \\
\hline & & \multirow[t]{2}{*}{ Mean } & \multirow[t]{2}{*}{$\begin{array}{c}\text { Std. } \\
\text { Deviation }\end{array}$} & \multirow[t]{2}{*}{$\begin{array}{l}\text { Std. Error } \\
\text { Mean }\end{array}$} & \multicolumn{2}{|c|}{$\begin{array}{l}\text { 95\% Confidence } \\
\text { Interval of the } \\
\text { Difference }\end{array}$} & & & \\
\hline & & & & & Lower & Upper & & & \\
\hline Pair 1 & TCS - TCS 2 & 5.68 & 8.31 & 0.48 & 4.74 & 6.62 & 11.89 & 302 & 0.000 \\
\hline Pair 2 & TDSP - TDSP 2 & 6.41 & 8.93 & 0.51 & 5.40 & 7.41 & 12.56 & 305 & 0.000 \\
\hline Pair 3 & TSKH - TSKH 2 & 3.33 & 7.34 & 0.42 & 2.51 & 4.16 & 7.95 & 303 & 0.000 \\
\hline Pair 4 & $\begin{array}{l}\text { TASKHOASDD - } \\
\text { TASKHOASDD } 2\end{array}$ & 2.34 & 8.03 & 0.46 & 1.44 & 3.24 & 5.11 & 306 & 0.000 \\
\hline Pair 5 & TASKHT - TASKHT 2 & 2.20 & 6.51 & 0.37 & 1.47 & 2.94 & 5.91 & 304 & 0.000 \\
\hline Pair 6 & TAPSSC - TAPSSC 2 & -3.46 & 8.19 & 0.47 & -4.39 & -2.54 & -7.35 & 301 & 0.000 \\
\hline
\end{tabular}

Source: Data collected and analysed by Nditafon (2016).

scored the items moderately high during pre-intervention also scored similar items moderately high during post-intervention for the TCS and TSKH constructs and similarly those who scored the items high at pre-intervention also scored same items high at post intervention in the TDSP, TASKHOASDD, TASKHT and TAPSSC constructs respectively.

Comparison of the mean scores revealed a significant difference between preand post-interventions in all the different constructs as displayed in Table 3. For example, in the identification of problem-solving characteristics of the human skeleton (TCS) summated mean scores varied from $(\mathrm{M}=39.88, \mathrm{SD}=7.59)$ at pre-intervention to $(\mathrm{M}=34.20, \mathrm{SD}=7.03)$ during post-intervention at $\mathrm{t}(302)=$ $11.89, \rho<0.001$ (2-tailed). The mean difference in this construct was found to be 5.68 within a $95 \%$ confidence interval ranging from 4.74 to 6.62 , Table 4 . The $\rho$-value of $<0.001$ does not say how large the effect of the intervention is, but simply the likelihood of rejecting the null hypothesis. To surmount this uncertainty Cohen's $d$ statistic was computed and found to be 0.68 , indicating a medium to large effect size [30]. In other words, the difference between the two means is 0.68 standard deviations from zero, where zero is the hypothesized dif- 
ference between the two means (i.e. the null hypothesis). On the strength of the $t$-test and Cohen's $d$ statistic, the null hypothesis of no significant different between mean scores in the pre- and post-intervention treatments was rejected. Hence, the alternative hypothesis of a significant difference between the treatments was upheld. Klopfer's taxonomy and the hypothetico-deductive thinking and reasoning model therefore, could have possibly contributed significantly to the development of the cognitive capacity of the students in identifying and describing the characteristics of the human skeleton using appropriate scientific terminologies. The responses provided by the respondents to the items of this variable during the post-intervention treatment could therefore not have been influenced by chance. Similar results were obtained for the rest of the constructs under investigation as in Table 3 and Table 4.

In conclusion, the null hypothesis of no significant difference between preand post-intervention treatments in this study was rejected in favour of the alternative hypothesis of a significant difference between treatments.

\subsection{Interaction-Main and Combined Effects of Selected Distal Variables}

Though the t-statistic all pointed to the fact that differences observed between pre- and post-intervention treatments were influenced by Klopfer's taxonomy and the candidate hypothetico-deductive thinking and reasoning model, it is not absolutely certain to draw such a conclusion because of the possible influence of distal factors discussed earlier in the methodology section of this report. To be fair about this assertion, statistical analyses of main and interaction effects of selected distal factors using factorial ANOVA and post-hoc multiple comparisons tests were conducted. Prior to this a Kolmogorov-Smirnov statistic with Liliefors significance correction $(\rho=0.0005)$ and the Sharpiro-Wilks lambda $(\rho=0.0005)$ tests confirmed the assumption of normality and absence of outliers for this parametric test in the distal data. There was good internal consistency assessed by Cronbach's reliability alpha ( $\alpha \geq 0.80)$, [29]. Careful examination of the tests of between-subjects effects statistic revealed a non-significant $(\rho>0.05)$ main and interaction effects of extremely small magnitudes for all three independent variables as in Table 5. For example:

1) Main interaction effect for: P5 (Zone of origin): $\mathrm{F}(3,279)=1.73 ; \rho=0.16$; and

2) Combined interaction effect: $\mathrm{P} 5 \times \mathrm{P} 4 \times \mathrm{P} 3$ (Region, age and sex of respondent respectively): $\mathrm{F}(4,279)=0.16 ; \rho=0.96$.

These results revealed that there were no significant differences in overall TAPSSC scores between respondents from different zones, in different age groups split into males and females. It equally suggested that the demographic factors under investigation had no effect on the student's ability to score the items on the dependent variable into the different levels of strongly agree, agree, can't say with certainty, disagree and strongly disagree. These variables had an 
Table 5. Tests of between-subjects effects on the outcome dependent variable: Appropriation and reinvestment of life skills in problem-solving.

\begin{tabular}{|c|c|c|c|c|c|c|c|}
\hline Source & $\begin{array}{l}\text { Type III Sum of } \\
\text { Squares }\end{array}$ & $\mathrm{df}$ & $\begin{array}{l}\text { Mean } \\
\text { Square }\end{array}$ & F & Sig. & $\begin{array}{c}\text { Partial } \\
\text { Eta } \\
\text { Squared }\end{array}$ & $\begin{array}{l}\text { Eta Squared } \\
\qquad\left(\eta^{2}\right)\end{array}$ \\
\hline $\begin{array}{c}\text { Corrected } \\
\text { Model }\end{array}$ & $1080.735^{\mathrm{a}}$ & 25 & 43.229 & 0.881 & 0.632 & 0.073 & 0.003 \\
\hline Intercept & 98536.780 & 1 & 98536.780 & 2009.001 & 0.000 & 0.878 & 0.264 \\
\hline P5 & 255.074 & 3 & 85.025 & 1.734 & 0.160 & 0.018 & 0.0007 \\
\hline $\mathrm{P} 4$ & 62.752 & 4 & 15.688 & 0.320 & 0.865 & 0.005 & 0.0002 \\
\hline P3 & 111.128 & 1 & 111.128 & 2.266 & 0.133 & 0.008 & 0.0003 \\
\hline $\mathrm{P} 5 \times \mathrm{P} 4$ & 278.091 & 7 & 39.727 & 0.810 & 0.580 & 0.020 & 0.0007 \\
\hline $\mathrm{P} 5 \times \mathrm{P} 3$ & 205.810 & 3 & 68.603 & 1.399 & 0.243 & 0.015 & 0.0006 \\
\hline $\mathrm{P} 4 \times \mathrm{P} 3$ & 278.615 & 3 & 92.872 & 1.893 & 0.131 & 0.020 & 0.0007 \\
\hline $\mathrm{P} 5 \times \mathrm{P} 4 \times \mathrm{P} 3$ & 31.925 & 4 & 7.981 & 0.163 & 0.957 & 0.002 & 0.00009 \\
\hline Error & 13684.294 & 279 & 49.048 & & & & \\
\hline Total & 373766.000 & 305 & & & & & \\
\hline $\begin{array}{l}\text { Corrected } \\
\text { Total }\end{array}$ & 14765.030 & 304 & & & & & \\
\hline
\end{tabular}

a. R Squared $=0.073$ (Adjusted R Squared $=-0.010$ ). Source: Data collected and analysed by Nditafon (2016).

extremely insignificant impact on student's performance in appropriation of the thinking process for real life contextual problem-solving as demonstrated by the extremely small eta squared statistic $\left(\eta^{2}=0.0007,0.0002\right.$, and 0.0003$)$ for zone, age group and gender respectively.

In conclusion therefore, demographic factors combined or not had no effect on the ability of the students to appropriate the thinking and problem-solving process differently during pre- and post-intervention treatments. The differences observed earlier in the pair-wise t-test of significance could then only have been brought about by the effect of Klopfer's taxonomy and the nature-semiotic hypothetico-deductive thinking and reasoning framework. These results are summarised in Table 5.

In a similar test to determine the main and interaction effects of the educational background of respondents the results presented in Table 6 were obtained:

These results revealed a significant main effect on respondent's performance by educational subsystem (English- and French-Speaking subsystems), at F (1, $299)=4.30, p=0.04$. Students of the English-Speaking subsystem had significantly different scores on the dependent outcome variable $(M=35.12)$ than their counterparts of the French-Speaking subsystem $(M=33.36)$ though the effect size was extremely small as seen from the eta squared value $\eta^{2}=0.0006$. Analysis for possible effects of school type attended by the respondents (lay private, denominational and public) also yielded a significant main effect for the different 
Table 6. Tests of between-subjects effects on the outcome dependent variable: Appropriation and transfer of life skills in problem-solving.

\begin{tabular}{|c|c|c|c|c|c|c|c|}
\hline Source & $\begin{array}{c}\text { Type III Sum } \\
\text { of Squares }\end{array}$ & df & $\begin{array}{l}\text { Mean } \\
\text { Square }\end{array}$ & F & Sig. & $\begin{array}{l}\text { Partial } \\
\text { Eta } \\
\text { Squared }\end{array}$ & $\begin{array}{c}\text { Eta } \\
\text { Squared } \\
\left(\eta^{2}\right)\end{array}$ \\
\hline Corrected Model & $591.049^{\mathrm{a}}$ & 5 & 118.210 & 2.494 & 0.031 & 0.040 & 0.002 \\
\hline Intercept & 282249.641 & 1 & 282249.641 & 5954.054 & 0.000 & 0.952 & 0.76 \\
\hline Educational Subsystem & 203.780 & 1 & 203.780 & 4.299 & $0.039^{*}$ & 0.014 & 0.0006 \\
\hline $\begin{array}{c}\text { Type of school (Lay } \\
\text { Private, Denominational } \\
\text { and Public) }\end{array}$ & 327.377 & 2 & 163.689 & 3.453 & $0.033^{\star}$ & 0.023 & 0.0009 \\
\hline $\mathrm{P} 1 \times \mathrm{P} 2$ & 0.985 & 2 & 0.492 & 0.010 & 0.990 & 0.000 & 0.000003 \\
\hline Error & 14173.980 & 299 & 47.405 & & & & \\
\hline Total & 373766.000 & 305 & & & & & \\
\hline Corrected Total & 14765.030 & 304 & & & & & \\
\hline
\end{tabular}

a. $\mathrm{R}$ Squared $=0.040$ (Adjusted R Squared $=0.024)$. ${ }^{\star}$ Significant at $\mathrm{p}<0.05$. Source: data collected and analysed by Nditafon (2016).

levels of the school type attended by the students, $F(2,299)=3.45, \mathrm{p}=0.03$ indicating that students in the Lay Private schools had significantly different scores on the dependent outcome variable than those from denominational and public schools with equally a very small magnitude (etasquared $\eta^{2}=0.0009$ ). Although the effect size is very small this constituted the most interesting and informative result because it indicated that differences observed in the population marginal means generated alongside the between-subject effect statistics depended on whether the respondent was English-Speaking or French-Speaking with students of the English-speaking subsystem demonstrating greater difficulty in appropriating the cognitive remediation thinking program for problem-solving in different contexts. Conversely, there was no interaction effect when the two independent variables were taken together, $\mathrm{F}(2,299)=0.01, \mathrm{p}=0.99$. However, having observed a significant main effect in the overall analysis of variance test, a post-hoc multiple comparisons was conducted to find the exact level of the influence. These results are presented in Table 7. From the results it was seen that there is a difference in performance only between the Lay Private institutions on the one hand and combined Denominational and Public institutions on the other hand. There was no difference between denominational and public institutions.

Comparisons of the two subsystems revealed that Upper Sixth English-speaking and Terminale D French-speaking students in Lay Private schools performed poorer on the outcome dependent variable than their counterparts in the denominational and public schools.

Finally, verification of the possible main and combined effects of selected social factors of interest in this study yielded a non-significant main and interaction effects for all three background factors investigated. However, in combination, all three factors have a significant effect. For example 
Table 7. Post-hoc multiple comparison (LSD) for school types (Lay Private, Private and Denominational) on the dependent outcome variable.

\begin{tabular}{|c|c|c|c|c|c|c|}
\hline \multirow{2}{*}{ (I) School } & \multirow{2}{*}{ (J) School } & \multirow{2}{*}{$\begin{array}{c}\text { Mean } \\
\text { Difference (I - J) }\end{array}$} & \multirow{2}{*}{$\begin{array}{l}\text { Std. } \\
\text { Error }\end{array}$} & \multirow{2}{*}{ Sig. } & \multicolumn{2}{|c|}{ 95\% Confidence Interval } \\
\hline & & & & & Lower Bound & Upper Bound \\
\hline \multirow{2}{*}{ Lay Private } & 2.00 & $2.0844^{*}$ & 1.01313 & 0.041 & 0.0906 & 4.0782 \\
\hline & 3.00 & $2.5687^{\star}$ & 0.94278 & 0.007 & 0.7134 & 4.4241 \\
\hline \multirow{2}{*}{ Denominational } & 1.00 & $-2.0844^{*}$ & 1.01313 & 0.041 & -4.0782 & -0.0906 \\
\hline & 3.00 & 0.4844 & 0.96316 & 0.615 & -1.4111 & 2.3798 \\
\hline \multirow{2}{*}{$\begin{array}{c}\text { Public } \\
\text { (Government) }\end{array}$} & 1.00 & $-2.5687^{\star}$ & 0.94278 & 0.007 & -4.4241 & -0.7134 \\
\hline & 2.00 & -0.4844 & 0.96316 & 0.615 & -2.3798 & 1.4111 \\
\hline
\end{tabular}

Based on observed means. The error term is Mean Square (Error) $=4.405 .{ }^{*}$ The mean difference is significant at the 0.05 level. Source: Data collected and analysed by Nditafon (2016).

Relationship with sponsor: $\mathrm{P} 6=\mathrm{F}(4,273)=0.84, \rho=0.50$; non-significant;

Educational level of respondent's sponsor: $\mathrm{P} 7=\mathrm{F}(4,273)=0.89, \rho=0.47$; non-significant;

Marital status of respondent's sponsor: $\mathrm{P} 8=\mathrm{F}(2,273)=1.22, \rho=0.30$; non-significant; and

In combination: $\mathrm{P} 6 \times \mathrm{P} 7 \times \mathrm{P} 8=\mathrm{F}(1,273)=5.32, \rho=0.02$ (significant).

These results further confirm that of the educational background and go on to show that acting in combination, the social background of the students of both the English- and French-speaking subsystems affect their ability to appropriate the cognitive remediation thinking and problem-solving tool. In the real world experiences Bouchard and McGue [31]; Betsworth, and co-workers [32]; and Mcleod [33] have variously demonstrated that life experiences are complex and often act in combination and rarely in isolation.

On the overall, it was concluded that the distal variables individually do not have an appreciable effect on the ability of respondents to appropriate and use the thinking program for problem-solving in present and different contexts except in the cases of the two subsystems of education taken separately, the lay private and denominational/public school types and the social background when taken in combination. Therefore within limits of these results, it can be concluded that in the greater part, the differences observed between the pre- and post-intervention treatments are brought about by Klopfer's taxonomy and the hypothetico-deductive thinking and reasoning program.

\section{Discussion}

The significance of the results especially indeciphering and stating the problem necessitating the possession of the characteristics and properties (TDSP) construct is that students acquired skills that enabled them to start identifying possible problems linked to solutions observed in nature after mediation informed by the hypothetico-deductive thinking and reasoning program. As a result, the problem-based approach to the teaching of biology and the experimental 
sciences Orange and co-workers [34] would appear favourable. This is possible if the nature-semiotic hypothetico-deductive thinking and reasoning model is adopted as the mediating tool in didactic transposition and teaching as demonstrated by the inferential statistics results. The small Cohen's effect size $d=0.45$ indicates that respondents had difficulties appropriating this concept. This could be due in part to the fact that in Cameroon secondary schools, teaching in the greater part ends at the level of dispensing declarative knowledge. There is little or no attempt to introduce the students to the concept of critical and inferential thinking (higher order thinking skills). These results justify the prescription of teaching critical and inferential thinking skills in Cameroon schools (Ministry of Secondary Education) [35] and more recently the competency-based approach with entry point being real life contextual problems as the new classroom practice for secondary education [1]. It is equally a useful first step in helping students learn how to mobilise their school knowledge to identify problems in their surroundings linked to the solutions provided by nature. Bringing students to start thinking about how nature has solved its own problems is a useful bridge onto thinking of how human beings can solve real life contextual problems. Deciphering and stating the problem solved by the possession of a characteristic therefore, is an indispensable hub in the development of the intellect, critical and inferential thinking skills in students. This step constitutes initiation into education.

With a Cohen's effect size $(d=0.72)$, the results on considering the characteristics of the skeleton as its know-how in solving problems (TSKH) have important significance as biology is essentially an observational science. Effective observation and measurement of phenomena and events in the learner's surrounding makes learning more meaningful as learners explore what is real and concrete to their lives before moving onto the abstract things which can only be perceived through logical and rational reasoning. As an observational science therefore, Vygotsky's [36]" more knowledgeable other" (MKO)—in this case the teacher, must help the students to make effective use of their senses of sight, touch, smell, hearing and taste. Building the effective use of the five senses into problem and know-how identification places the thinking program in congruence with Feuerstein's principle of intentionality and reciprocity in the cognitive modifiability mediation process, [37] [38]. Once this skill is acquired, it becomes easy for the student to formulate the observed characteristic into a solution and therefore pose the premise that such a characteristic is solution to a problem. Considering a characteristic as solution to a problem in other words is considering it as a know-how. This stage in the thinking model is equally crucial as it ties the concept of know-how to a specific problem situation.

The results from the foregone three constructs (TCS, TDSP, TSKH) agree with Bachelard's [39] [40] findings which asserts that a child from its first contact with life finds itself confronted by a world that poses a lot of questions. The child's spontaneous instinct is to proceed to find answers to these questions ei- 
ther individually or through interaction with its entourage. Effective interaction with the surrounding requires effective observation and effective observation must be mediated with a definite intention in mind [37] [38] [41] [42]. Due to lack of a scientific mediation of the child's initial observations, Bachelard refers to knowledge acquired in such ways as "common knowledge". The pre-intervention performances of the students confirm the acquisition in the greater part by the student of Bachelard's common knowledge. After the introduction of the nature-semiotic hypothetico-deductive thinking program, performances at post-intervention showed significant gains compared to pre-intervention. The hypothetico-deductive thinking and reasoning model therefore provided a structured scientific framework for student thinking, reasoning, problem-based learning and solution-seeking techniques. Bachelard refers to knowledge acquired in this way as "scientific knowledge". Therefore, effective and mediated problem-based or solution-seeking observations are important steps in the acquisition of scientific knowledge. The post-intervention inferential statistics in this category provides evidence that the hypothetico-deductive model can help the students to restructure their observation and therefore learn in a scientific way geared towards societal problem-solving.

Concerning the constructs "application of the skeleton's know-how in other areas of the same discipline and in other disciplines (TASKHOASDD)" and "application of the skeleton's know-how in technology and society (TASKHT)", respondents during post-intervention showed mastery of the thinking process compared to their performances at pre-intervention. This implied that the hypothetico-deductive thinking and reasoning model acting as guide supported student's appropriation and use of analogical thinking to transfer learning from one context of use to another. However, compared to the TCS, TDSP and TSKH constructs discussed above, respondents exhibited increasing difficulties in proceeding to find analogues of the identified know-how in other areas of the same discipline, other disciplines and in science and technology including society in that order. This is justified by the small effect size (Cohen's $d=0.29$ and 0.34 respectively), of the model on their ability to bridge the knowledge learned in one context to find analogues in novel contexts. During the experimentation however, a rubric that emphasised the interpolation and extrapolation of the knowledge acquired to other areas for problem-solving was associated with the mediation process. This possibly accounted in part for the improved performances of respondents in the post- than in the pre-intervention. Effective teaching of the sciences therefore should bring out the linkages between the knowledge acquired in one field with similar situations in the same discipline, other disciplines and in technology including society. Such skills once acquired can be extrapolated to other areas of life including problem-solving. Identifying problems in nature and the way nature sets about solving them can also be extrapolated to similar problems in different areas including technology and the human society. With the introduction of the hypothetico-deductive thinking 
framework, respondents were systematically helped to sought for and find the links in their school knowledge in other areas of the same discipline, other disciplines, and in technology including society. By systematically studying the way nature solves its problems and linking such to the human society, school knowledge is being put into its context-of-use [6]. Hence teachers ought to accompany all mediation actions with activities and exercises that will lead to greater mastery of the concept of transcendence, to ensure that students expand their horizons of thinking and apply scientific knowledge in problem-solving in novel contexts. These results equally agree with the principles of intentionality and reciprocity, mediation of meaning and transcendence [43], cited by Tan [44]. These principles according to Feuerstein [37] develops in the child a deeper understanding of the world, a perception of how things are interconnected, a curiosity to inquire and discover relationships between things and a desire to know more about things and seek explanations. Mediation involves finding a general rule that applies to related situations; linking events in the present with the future and the past; engaging one in reflective thinking to reach an underlying understanding of a situation; and enabling thinking laterally about experiences and issues [37] [41] [45]. Additionally, these results also corroborate the findings of Olajide and Adeoye [46] who, working on the effects of analogical reasoning and extended wait time on achievement in biology came to the conclusion that analogical reasoning has a great impact on achievement in science and it really helps students' understanding and the effect is immediate. The results also agree with the findings of Gentner and Ratterman [47], Halford [48], Richlandsnd colleagues [49], all cited by Vendetti and Co [50] that students needed additional support to notice and successfully use analogical reasoning in learning contexts. In the case of this study, the hypothetico-deductive model provides such support. By appropriating analogical reasoning, students are unconsciously engaging the appropriate neural networks by conditioning them to process analogies, thereby expanding their horizon about the piece of knowledge learned. This type of thinking should logically lead to the transferability of knowledge, know-how, skills and methods learned in one context to a novel context in seeking solutions to real life problems now and for the unknown. By learning to interpolate and extrapolate knowledge and skills using the technique of analogies to discover similar applications in novel contexts to similar problems, students are intrinsically building the skills for transferability, the feeling of competence and autonomy of thought and action in them [6]. This equally implies that in the mediation of learning experiences of students, teachers ought to associate the mediation of transferability, the feeling of competence and autonomy of thought and action. Transferring a piece of knowledge or skill or method learned in one context to a novel context in order to find analogues of that piece of knowledge, skill or methodology for problem-solving requires critical and inferential thinking and mind-mapping. In a study on helping minority students to succeed in a technological college, Kozulin and others [42] demonstrated that the Instru- 
mental Enrichment (IE) tool of professor Feuerstein, used to mediate student's learning experiences for cognitive modifiability in a particular subject area led to enhanced self-confidence of the experimental group. Therefore by including the intention of cultivating meaning, self-confidence and competence, students invariably develop and appropriate these skills, leading to autonomy of thought and action. The process of interpolation and extrapolation to find analogues of the application of an identified know-how in other areas of the same discipline, other disciplines and in technology and society, triggers in the student an inner self-conflict of judgment, comparison as well as the discarding and upholding of ideas which cross their minds in an effort to establish the suitability of the analogues they find. Hence this process leads to introspection and metacognition-thinking about one's own thoughts. Winn [51] agrees with other scientists that the notion of internalized symbol systems serve as cognitive tools. Educational technologists have been particularly interested in this research on how the symbolic systems of computers can "become cognitive". The internalization of the symbolic operations of computers led to the development of a word processor, called the "Writing Partner" that helped students write [52]. The results of a number of experiments showed that interacting with the computer led the users to internalize a number of its ways of processing, which led to improved metacognition relevant to the writing task. By developing inspiration from nature's characteristics as semiotic tools for mediating the thinking and learning process, the hypothetico-deductive cognitive mediation toolin this study bears a striking similitude to the Winn and Salomon's "Writing Partner". Analogues, including even the most remote that is not readily evident provide evidence for similitude between structures and functions and the use to which such adaptations are put in technology and society to solve societal problems. For example a computer case that houses and protects the delicate electronic circuits and processors and a handset (telephone) that equally houses and protects the delicate electronic circuits of a telephone all bear striking similitude to the cranial box that houses and protects the soft delicate human brain. The different pieces of the bones of the cranial box are flat and joined together by Sharpey's fibres. The metal or semi-metal and plastic pieces that make up the computer and telephone cases are assembled together with screws and glues that play the same role like the Sharpey fibres in the skull. Inferring analogues from nature's know-how opens up a new horizon for creative thinking. Creativity and innovation are necessary skills in very high demands in present day rapidly metamorphosing technological and electronic environment. Airplanes are technological analogues of birds, human robots are technological analogues of human beings, artificial intelligence and computer circuits are technological analogues of the human brain. Hence transcendence (bridging) during the stage of finding analogues of an identified know-how in other areas of the same discipline, other disciplines and technology is a transient strategy for favouring the cultivation of knowledge transfer, development of creative and innovative skills in thinking and prob- 
lem-solving among students. By expanding thought processes in this way, learners are helped to cultivate the attitude of thinking and reasoning outside the box. It is therefore the conviction of these authors that the hypothetico-deductive thinking and reasoning model combined with the appropriate dose of mediation, can achieve this.

With respect to the educational background of the respondents in this study, there was evidence for a significant main effect on the appropriation of the model between English-speaking and French-speaking students, with French-speaking students appropriating the process better than their English-speaking counterparts. This could be explained in part by the fact that logical thinking and reasoning are introduced to French-speaking students earlier in their school life through the teaching of Philosophy in both the first and second cycles. Conversely, the English-speaking child in Cameroon does not have a similar exposure. Worse still, an English-speaking science student is completely alienated from Philosophy, which introduces the basic concepts of logic, thinking, reasoning and the origin of knowledge. Evidence for a significant main effect of the prior school type attended by the respondents (lay-private, denominational and public) was also found showing that denominational and public institutions mastered the concept better than the lay-private institutions. It is difficult to justify these statistical findings though some factors appear to militate in favour of this state of affairs, namely:

1) while public and denominational institutions select the best candidates through the variously organized entrance examinations, the weak and often rejected candidates are absorbed by the lay-private school;

2) academically weak students who have been dismissed for poor academic performances compounded by disruptive behavior are readily absorbed by the lay-private institutions;

3) lay-private school teachers are hardly full time and in the most part are very poorly paid.

This study also provided evidence for a combined significant effect in the social background of the students.

The distal variables investigated in this study, are similar to Tzuriel's [53] distal or adverse factors. Klein [54], Klein and Aloni [55], Tzuriel and Weiss [56], Tzuriel and Eran [57], reported some evidence of the effects of age, context, sex and cultural background on the mediated learning experiences of developing children. This finding is at variance with the results of this study which had demonstrated that there is neither significant main effect nor interaction effect of age, sex and zone of origin on student's appropriation of the thinking program. This discrepancy in findings could be explained by a number of factors amongst which are the differences in cultural backgrounds of Tzuriel's respondents and those of this study, as well as the use of the explicit approach to the teaching of critical thinking skills by Tzuriel as opposed to the embedded or infusion method used in this study. While it can be argued that the hypotheti- 
co-deductive thinking program is not the same as Feuerstein's Instrumental Enrichment tool used by Tzuriel, it should be noted that both tools are mediating tools for mediating learning, thinking and problem-solving processes with inbuilt intentionality/reciprocity, meaning and transcendence/bridging. Marin and Halpern [4] agree that both explicit and embedded instructional approaches can develop critical thinking with each method having its strengths, weaknesses and place in education. This assertion is further confirmed by Swartz and McGuinness [3] who suggests that three key principles cut across both explicit and infused approaches in the teaching of critical thinking and transferability namely: 1) the impact on students is greater the more explicit the teaching is; 2 ) students value critical thinking more as classroom instruction incorporates greater atmosphere of thoughtfulness; 3) Students think more about what they are learning when the teaching of thinking is infused more and more into content. Marin andHalpern [4] and Cotton [58], all affirm that there is substantial research evidence that supports both methods and therefore there is no reason to consider them mutually exclusive.

\section{Some practical and academic significance of this study}

The study finds relevance and is therefore significant in the fields of 1) didactics of the experimental sciences; 2) epistemology of experimental sciences; and in 3) pedagogic practices. From the didactical point of view, the hypothetico-deductuve thinking and reasoning framework is a didactisation tool which informs internal didactic transposition, teaching and learning of the experimental sciences. Due to the tool's inbuilt characteristic of bridging, the transfer of knowledge learned in one context for application in other contexts, it poses as a suitable mediator of the didactic situation. Once mastered and appropriated therefore, the student will quickly attain Brousseau's [6] adidactical situation, wherein the teacher's influence and mediation role is gradually reduced as learning proceeds from the simple to the abstract. As a mediating tool that places the learner at the centre of his/her learning, it guarantees the development of self-confidence, and autonomy of thought and action and therefore competences for contextual problem-solving. Epistemologically, the tool favours the development of new knowledge which favours the growth of the discipline. Through the use of its transcending mechanism, similitudes are established and this constitutes a new way of contributing to the growth in content of the discipline, within the scientific rigour of a discipline which includes a domain or field of study, content, methodology and expertise. For example, striking similitude exist between the male reproductive organ (penis-long tube-like structure) for delivery of spermatozoa into the female vagina and pollen tube of flowering plants for delivery of pollen nucleus into the ovary as well as drip sets for delivering medicaments into the veins of patients. By adopting analogical thinking techniques, the tool serves as a veritable epistemological instrument for generating new knowledge. On the pedagogic side of the continuum, the innovative methodological approach offered by this study should facilitate the preparation and 
teaching of inspiring and problem-based lessons that favour learner-centred rather than teacher-centred classroom practice. If mastered, it offers the opportunity to teachers to adopt Problem-Based Learning (PBL) in which:

1) learning is driven by challenging, open-ended problems with no one "right" answer;

2) problems/cases are context specific, establishing the contextual relevance of school knowledge;

3) students work as self-directed, active investigators and problem-solvers in collaborative groups; and

4) teachers appropriate their role of facilitation, guiding the learning process and promoting an environment of inquiry, contextual problem-solving and exchange.

Rather than have a teacher provide facts and then test student's ability to recall these facts via memorization, PBL attempts to get students to apply knowledge to new situations. Overall, the study provides direct relevance to the educational system of Cameroon especially, with the on-going reforms in secondary education that prescribes the competency-based approach with entry point into lessons being real life contextual situations, (see for example [34]. It can therefore be state without fear of contradiction that the study:

1) provides a set of strategies that students can use again and again to make informed decisions and judgments when faced with problems in novel contexts;

2) increases students' interest and motivation in learning both critical thinking skills and science lesson content since thinking skills are infused into the lesson; and

3) provides opportunity for the same content material to be used to teach a wide variety of critical thinking skills such as compare and contrast; problem-solving; making informed decisions and acting on them with confidence; making inferences; making judgments; causal reasoning; argument; prediction; and creativity, amongst others.

\section{Limitations}

Limitations in this study include among others the fact that the study:

1) used a researcher-made questionnaire which may have inherent errors that may need refinement in future researches;

2) used only students in the investigation whereas in a typical didactic situation there are four components (learner, teacher, knowledge and the situation). Future studies should widen the horizon of the research to include the other components that have not been investigated;

3) was limited to the use of Likert scale type questionnaire that was summated into a continuous scale for quantitative analyses. A multiple choice test with scores in pre- and post-interventions as well as qualitative observation could be more elucidating in future studies;

4) could not adopt a true experimental design because it had to be conducted 
in schools with already pre-existing structures and defined programs of study. Parents and school authorities usually resist the idea of reorganizing already existing class structures for the purpose of experimentation.

5) parents particularly do not appreciate the use of their children in experimentation and so the informed concern was not easy to obtain.

\section{Conclusion and Perspectives}

This study demonstrates how the nature-semiotic hypothetico-deductive thinking and reasoning program triggers structured thinking as well as "thinking out of the box" through the seeking of analogies using interpolation and extrapolation as bridging techniques. This way of thinking broadens student's thinking horizons, developing creative, innovative, critical and inferential thinking skills and competences. All of these confer on the student the feeling of autonomy of action and thought and therefore flexibility and open-mindedness in searching for relevant problem-solving cues when faced with a problem situation. The advantage of this framework is that once appropriated, students can apply it to existing real life situations now and in the future.

In conclusion therefore, one of the best ways for ensuring that school knowledge is used to solve societal problems and therefore establish a clear link between school and society is to turn to nature and copy from its perfect and precise skills in problem-solving. Interpolating and extrapolating as well as reinvesting such knowledge, skills and scientific methodologies to seek solutions to societal challenges establish the bridge between school knowledge and the society. The ability to appropriate this way of thinking, transferring knowledge and solving societal problems constitutes higher order intellectual attainment as it enables learners to handle abstractions and logical operations as a result of interaction with their physical and the socio-cultural environments. This widens learner's scope of thinking, transferability and applicability of knowledge, skills and methods learned in the classroom for problem-solving in novel contexts in society. Work in progress seeks to demonstrate how the hypothetico-deductive thinking and reasoning candidate theory of didactic transposition, teaching and learning of the experimental sciences (Nditafon et al., 2016) can be used as a tool to foster the development of meta-cognition skills and chunking in students.

\section{Conflicts of Interest}

The authors declare no conflicts of interest regarding the publication of this paper.

\section{References}

[1] MoSE (2014) Ministerial Arête No. 491/14/MINESEC/IGE of 9 December 2014 to Outline the Syllabuses for Forms III, IV and V of Secondary General Education; All for the English-Speaking Subsystem; and Ministerial Order No. 264/14/MINESEC/IGE of $13^{\text {th }}$ August 2014 to Outline the Syllabuses for Form 1 and Form 2 of Secondary General Education. 
[2] Nditafon, G.N., Noumi, E., Nkeck Bidias, S.R. and Nchia, L.N. (2016) Hypothetico-Deductive Thinking Model: Candidate Theory and Mechanism for Didactic Transposition and Teaching of the Experimental Sciences. American Scientific Research Journal for Engineering, Technology and Sciences (ASRJETS), 26, 185-203. http://asrjetsjournal.org

[3] Swartz, R.J. and McGuinness, C. (2014) Developing and Assessing Thinking Skills. The International Baccalaureat Project 2014. Final Report Part 1. Literature Review and Evaluation Framework.

[4] Marin, L.M. and Halpern, D.F. (2010) Pedagogy for Developing Critical Thinking in Adolescents: Explicit Instruction Produces Greatest Gains. Thinking Skills and Creativity, 6, 1-13.

[5] Reed, J. (1998) Effect of a Model for Critical Thinking on Student Achievement in Primary Source Document Analysis and Interpretation, Argumentative Reasoning, Critical Thinking Dispositions and History Content in a Community College History Course. PhD Diss., College of Education, University of South Florida, Tampa.

[6] Brousseau, G. (1997) Theory of Didactical Situations in Mathematics. Kluwer, Dordrecht.

[7] Noumi, E. and Nditafon, G.N. (2015) Didactic Transposition of the Alternative Knowledge of the Brazilian Telenovela "O Clone" to Knowledge Taught. International Journal of Science and Research (IJSR), 4, 508-519. http://www.ijsr.net/

[8] Mothia, J., Noumi, E. and Nditafon, G. (2015) Developing Thinking Skills among Third Grade (Class 4) Pupils in Some Elementary Practising Schools in Edéa, Cameroon Using Lessons on the Human Skeleton. Open Access Library Journal, 2, e2071. https://doi.org/10.4236/oalib.1102071

[9] Fisher, A. (2007) Critical Thinking: An Introduction. Cambridge University Press, Cambridge, England. http://www.nwrel.org

[10] Paul, R., Linda, E. and Ted, B. (1997) California Teacher Preparation for Instruction in Critical Thinking: Research Findings and Policy Recommendations. California Commission of Teacher Credentialing, Sacramento, CA.

[11] Stapleton, P. (2011) A Survey of Attitudes towards Critical Thinking among Hong Kong Secondary School Teachers: Implications for Policy Change. Education Resources Information Center, ERIC No. EJ915705.

https://doi.org/10.1016/j.tsc.2010.11.002

[12] Thurman, B. (2009) Teaching of Critical Thinking Skills in the English Content Area in South Dakota Public High Schools and Colleges. Education Resources Information Center, ERIC No. ED513229.

[13] Bataineh, O. and Alazzi, K. (2009) Perceptions of Jordanian Secondary Schools Teachers towards Critical Thinking. Education Resources Information Center, ERIC No. EJ869429.

[14] Beyer, B. (2001) What Research Says about Teaching Thinking Skills. In: Costa, A.L., Ed., Developing Minds. A Resource Book for Teaching Thinking, Association for Supervision and Curriculum Development, Alexandria, VA, 275-282.

[15] Hatcher, D.L. (2006) Stand-Alone versus Integrated Critical Thinking Courses. Journal of General Education, 55, 247-272. https://doi.org/10.1353/jge.2007.0002

[16] Klopfer, L.E. (1970) Student Behaviour and Science Content Categories and Subcategories for a Science Program. Pittsburg University Press, Pittsburg, 1-62.

[17] Nditafon, G.N. and Noumi, E. (2014) Enhancing the Construction and Appropriation of Scientific Knowledge for Reinvestment in Seeking Solutions to Problems in 
New Contexts: Case of a Lesson on Sexual Reproduction in Flowering Plants among Second Year Learners of General Secondary Education in Yaoundé, Cameroon. International Journal of Science and Research, 3, 692-695. http://www.ijsr.net

[18] De Landsheere, G. (1979) Dictionnaire de l'évaluation et de la recherche en éducation. PUF, Paris, $338 \mathrm{p}$.

[19] Nevo, B. (1985) Face Validity Revisited. Educational Measurement, 22, 287-293. https://doi.org/10.1111/j.1745-3984.1985.tb01065.x

[20] Zikmund, W.G. (2003) Business Research Methods. 7th Edition, Thomson/ South-Western.

[21] Tabachnick, B.G. and Fidell, L.S. (2007) Using Multivariate Statistics. Pearson Education Inc., Boston.

[22] Pallant, J. (2005) SPSS Survival Manual: A Step by Step Guide to Data Analysis Using SPSS for Windows (Version 12). Allen and Unwin, Crow's Nest NSW.

[23] Salkind, N.J. (2000) Exploring Research. Fourth Edition, Prentice Hall, Upper Saddle River.

[24] Levine, T.R. and Hullet, C.R. (2002) Eta Squared, Partial Eta Squared, and Misreporting of Effect Size in Communication Research. Human Communication Research, 28, 612-625. https://doi.org/10.1111/j.1468-2958.2002.tb00828.x

[25] Abelson, R.P. (1995) Statistics as Principled Argument. Erlbaum, Hillsdale.

[26] Keppel, G. (1982) Design and Analysis. Prentice Hall, Englewood Cliffs.

[27] Kerlinger, F.N. (1986) Foundations of Behavioral Research. Holt, Rinehart and Winston, New York.

[28] Kirk, R.E. (1995) Experimental Design. Brooks Cole, Pacific Grove.

[29] George, D. and Mallery, P. (2003) SPSS for Windows Step by Step: A Simple Guide and Reference. 11.0 Update, 4th Edition, Allyn and Bacon, Boston.

[30] Cohen, J. (1988) Statistical Power Analysis for the Behavioral Sciences. 2nd Edition, Lawrence Erlbaum Associates.

[31] Bouchard, T.J. and McGue, M. (2003) Genetic and Environmental Influences on Human Psychological Differences. Wiley Periodicals, Inc., Wilmington.

http://www.interscience.wiley.com https://doi.org/10.1002/neu.10160

[32] Betsworth, D.G., Bouchard, T.J., Cooper, C.R., Grotevant, H.D., Hansen, J.C., Scarr, S. and Weinberg, R.A. (1994) Genetic and Environmental Influences on Vocational Interests Assessed Using Adoptive and Biological Families and Twins Reared Apart and Together. Journal of Vocational Behavior, 44, 263-278.

https://doi.org/10.1006/jvbe.1994.1018

[33] Mcleod, J. (1974) System Theory and Simulation. Behavioural Science, 19, 57-69.

[34] Orange, C., Beorchia, F., Ducrocq, P. and Orange, D. (1999) Réel du terrain, Réel de laboratoire et consruction de problèmes en sciences de la vie et de la terre. Aster, 28, 108-129.

[35] MoSE (1998) Law No. 98/004 of 11 April 1998 to Lay down Guidelines for Education in Cameroon. Presidency of the Republic, 9 p.

[36] Vygotsky, L.S. (1987) Thinking and Speech. In: Rieber, R.W. and Carton, A.S., Eds., The Collected Works of L. S. Vygotsky, Vol. 1. Problems of General Psychology, Plenum, New York, 39-285.

[37] Feuerstein, R. (1990) The Theory of Structural Modifiability. In: Presseisen, B., Ed., Learning and Thinking Styles. Classroom Interaction, National Education Associa- 
tion, Washington DC.

[38] Feuerstein, R., Rand, Y., Hoffman, M. and Miller, R. (1980) Instrumental Enrichment: An Intervention Program for Cognitive Modifiability. University Park Press, Baltimore.

[39] Bachelard, G. (1938) La formation de l'esprit scientifique. Vrin, Paris.

[40] Bachelard, G. (1989) La formation de l'esprit scientifique. 14ème édition, Vrin, Paris, $256 \mathrm{p}$.

[41] Tzuriel, D. (2013) Mediated Learning Experience Strategies and Cognitive Modifiability. Journal of Cognitive Education and Psychology, 13, 59-80. https://doi.org/10.1891/1945-8959.12.1.59

[42] Kozulin, A., Lebeer, J., Madella-Noja, A., Gonzalez, F., Jeffrey, I., Rosenthal, N. and Koslowsky, M. (2010) Cognitive Modifiability of Children with Developmental Disabilities: A Multicentre Study Using Feuerstein's Instrumental Enrichment-Basic Program. Research in Developmental Disabilities.

[43] Feuerstein, R. and Feuerstein, S. (1991) Mediated Learning Experience: A Theoretical Review. In: Feuerstein, R., Klein, P.S. and Tannenbaum, A.J., Eds., Mediated Learning Experience: Theoretical, Psychological and Learning Implications, Freund, London, 3-51.

[44] Seng, T.O. (2003) Mediated Learning and Pedagogy: Application of Feuerstein's Theory in Twenty-First Century Education. React, 22, 53-63.

[45] Seng, S.H. (1997) Using Mediated Learning Experiences to Enhance Children's Thinking. Annual International Study Conference of the Association for Childhood Education International, Portland, 9-12 April 1997, 1-11.

[46] Olajide, J.O. and Adeoye, F.A. (2010) The Effect of Analogical Reasoning and Extended Wait Time on Achievement in Biology. International Journal of Science Education, 2, 21-28.

[47] Gentner, D. and Ratterman, M.J. (1991) Language and the Career of Similarity. In: Gelman, S.A. and Byrnes, J.P., Eds., Perspectives on Thought and Language: Interrelations in Development, Cambridge University Press, Cambridge, 225-277. https://doi.org/10.1017/CBO9780511983689.008

[48] Halford, G.S. (1992) Analogical Reasoning and Conceptual Complexity in Cognitive Development. Human Development, 35, 193-217. https://doi.org/10.1159/000277167

[49] Richland, L.E., Morrison, R.G. and Holyoak, K.J. (2006) Children's Development of Analogical Reasoning: Insights from Scene Analogy Problems. Journal of Experimental Child Psychology, 94, 249-273. https://doi.org/10.1016/j.jecp.2006.02.002

[50] Vendetti, M.S., Bryan, J., Matlen, B.J., Richland, L.E. and Bunge, S.A. (2015) Analogical Reasoning in the Classroom: Insights from Cognitive Science. Mind, Brain, and Education, 9, 100-106. https://doi.org/10.1111/mbe.12080

[51] Winn, W. (2004) Cognitive Perspectives in Psychology. In: Jonassen, D.H., Ed., Handbook of Educational Communications and Technology: A Project of the Association of Educational Communications and Technology, Lawrence Erlbaum Associates, Mahwah, New Jersey.

[52] Salomon, G., Perkins, D.N. and Globerson, T. (1991) Partners in Cognition: Extending Human Intelligence with Intelligent Technologies. Educational Researcher, 20, 2-9. https://doi.org/10.3102/0013189X020003002

[53] Tzuriel, D. (2011) Mediated Learning and Cognitive Modifiability. In: Seel, N.M., 
Ed., Encyclopedia of Sciences of Learning, Springer Publishing, New York, 2154-2157.

[54] Klein, P.S. (1988) Stability and Change in Interaction of Israeli Mothers and Infants. Infant Behavior and Development, 11, 55-70. https://doi.org/10.1016/S0163-6383(88)80016-X

[55] Klein, P.S. and Aloni, S. (1993) Immediate and Sustained Effects of Maternal Mediation Behaviors on Young Children. Journal of Early Intervention, 17, 1-17. https://doi.org/10.1177/105381519301700208

[56] Tzuriel, D. and Weiss, S. (1998) The Effects of Mothers' Acceptance/Rejection Attitudes, Children's Personality and Mothers' Mediated Learning Strategies on Cognitive Modifiability. Early Development and Parenting, 7, 79-99. https://doi.org/10.1002/(SICI)1099-0917(199806)7:2<79::AID-EDP166>3.0.CO;2-\#

[57] Tzuriel, D. and Eran, Z. (1990) Inferential Cognitive Modifiability of Kibbutz Young Children as a Function of Mother-Child Mediated Learning Experience (MLE) Interactions. International Journal of Cognitive Education and Mediated Learning, 1, 103-117.

[58] Cotton, K. (1991) Close-Up\#11: Teaching Thinking Skills. Retrieved 05/12/2016, from Northwest Regional Educational Laboratory's School Improvement Research Series Website. http://www.nwrel.org 